\title{
Increasing Public Participation and Influence in Local Decision-making to Address Social Determinants of Health During Times of Resource Constraint: A Systematic Review Examining Initiatives and Theories
}

Susan Baxter ( $\nabla$ s.k.baxter@sheffield.ac.uk)

The University of Sheffield https://orcid.org/0000-0002-6034-5495

\section{Amy Barnes}

The University of Sheffield

\section{Caroline Lee}

University of Cambridge

\section{Rebecca Mead}

Lancaster University

\section{Mark Clowes}

The University of Sheffield

\section{Research article}

Keywords: public involvement, local decision-making, public participation, public influence, citizen control, delegated power, local government, financial constraints

Posted Date: August 28th, 2020

DOl: https://doi.org/10.21203/rs.3.rs-60034/v1

License: (c) (i) This work is licensed under a Creative Commons Attribution 4.0 International License. Read Full License 


\section{Abstract}

Background: Creating conditions for people to exert influence and control within their lives is an important determinant of health, and crucial in addressing health inequity. Globally, governments, communities, and other partners are experimenting with initiatives to support public participation at a local level. Little is known about how different approaches work, and how changing economic circumstances including the worldwide financial crisis and COVID-19 pandemic create challenging circumstances for implementation. This review examined evidence on initiatives to increase peoples' involvement in local decision-making, with a focus on how this may be affected by resource constraints.

Methods: We carried out a mixed-method systematic review of European empirical literature published since 2008, on initiatives aiming to increase public participation in local decision-making/action which could affect public health outcomes. We supplemented this with worldwide literature outlining theories and frameworks to explore potential change pathways. We used narrative synthesis to analyse the literature identified, and a summary diagram to provide a reporting structure.

Results: We included 42 documents. Much literature was from the United Kingdom, and of qualitative or case study design. There was limited reporting of the forms and intended/actual functions of initiatives to enhance public participation and influence. Diverse factors (organisational and community-related factors, features of the participatory process) were noted to shape pathways to potential outcomes. Positive and adverse outcomes were reported for communities, individuals, relationships, and the decision-making process. The review highlights how initiatives may be at risk during times of limited resourcing; undermining individual and community capacities to participate, and requiring organisational leaders to think/act differently.

Conclusions: Areas to prioritise for action within local governance systems include: supporting community capabilities; relationships between organisations and communities; creating spaces for safe/equitable interaction and knowledge-sharing; and changing institutional culture. If investment is to be made by local governments or communities themselves in times of resource-constraint, there is an urgent need to clarify the functions of different activities and pathways to improvements in determinants of health and inequity. Support to enable change is needed, particularly in response to deep-seated issues within local governance systems, and more explicit engagement with concepts of politics and power.

\section{Background}

Health inequities stem from unequal social, material and political conditions in which people are born, grow, live, work and age; and are typically referred to as social determinants of health (1). Unequal conditions affect people's access to rights, capabilities and resources, shaping experiences in childhood; opportunities to access play, recreation and learning; access to decent work, housing and services and thus lifelong health and wellbeing $(2,3)$. There is growing evidence that lack of control over decisions and actions that shape our lives and health is an important determinant of poor health; thus creating 
conditions for people to exert influence and control is crucial in addressing health inequity $(4,5)$. Recent evidence suggests that more than ever people want to have a greater say in shaping policy actions that affect their lives (6). For example, in England, the Community Life Survey 2018-2019 reported that 52\% of adults wanted more involvement in local decision-making, with only $25 \%$ feeling able to influence decisions affecting their local area (7). These concerns have been recognised by recent World Health Organization health and development policy; with the 2030 Agenda for Sustainable Development outlining a global commitment to further inclusive and participatory decision-making at all levels: from the global to the local (8).

At a local level across the globe, local governments, communities, and other organisational partners are experimenting with different approaches to increase public participation and influence in decisions and action at regional, city and/or neighbourhood levels, in ways that could improve determinants of health $(6,9)$. Yet little is known about how different approaches work to support people's influence in local decision-making and actions that affect their lives. Recent academic work has furthered conceptual understanding of potential pathways between influence and control in day-to-day living environments and health inequalities (10), and of the potentially differential effects of community engagement in public health interventions more generally (11). However, we also need to more fully understand how approaches to increase public influence in local decision-making and action work in practice, and the ways whereby influence is exerted. Also, what are the effects on social, material and political conditions that shape health and inequities within different contexts. Moreover, following the financial crisis of $2007 / 2008$ the reality of constrained resources (particularly in Europe) is highly significant to the economic context for local governments, communities and their organisational partners (12). Deep cuts to local government budgets due to subsequent austerity policies have been experienced in the context of "the wider costs of recession" (13). The anticipated social and economic crisis in Europe resulting from the recent COVID-19 pandemic is likely to further constrain local resources and entrench health inequities (14).

This systematic review aimed to identify approaches to increase people's participation and influence in local-level decision-making and actions which affect their lives and where they live. It aimed to explore how different approaches improve (or are theorised to) improve other social determinants of health. Given the challenges in local governance highlighted above, the review aimed to particularly identify evidence relating to public influence in a context of limited financial resources. Key areas of focus were:

- How effective are different approaches are that seek to give people opportunities to influence decision-making and action that affects their lives and where they live?

- What factors affect how people are involved and can influence decision-making?

- What are the outcomes of different approaches in terms of influence, other wider determinants of health, and long-term health and health inequities?

- How do resource constraints shape all the above? 


\section{Methods}

A protocol for the review was developed and is available at https://www.crd.york.ac.uk/PROSPERO registration number CRD42019154748.

\section{Eligibility criteria}

Population - We included empirical studies on initiatives to increase public participation and influence within any European country. Initial scoping work indicated that there was a substantial body of literature available, and we were most interested in studies which would offer the greatest relevance for interventions in the UK.

Interventions - Our focus was on initiatives, strategies, or programmes which had the purpose of giving individuals or groups increased opportunity to influence local-level decisions and actions. The actions would potentially affect people's living conditions (social determinants of health) and other public health outcomes. Drawing on Arnstein's Ladder of Citizen Participation (15) we were interested in initiatives which were about "citizen power" (including partnership, delegation, delegated power, and citizen control), which may be referred to as participation and involvement. By understanding influence as "citizen power" in this way, we wanted to identify evidence of approaches that supported people to have an effect on the actions and decision-making choices of others (e.g. local government, community partners) locally, as well as the capacity to redefine structures, institutions and organisational contexts (16). We excluded literature relating to informing or providing information, and also that which related to public/community engagement where there was no apparent opportunity to influence decision-making or action. We also excluded studies which described public involvement/influence in an advisory capacity during research studies.

Outcomes - We included initiatives with the purpose of increasing the influence/power/control of members of the public in local decisions and action that affected the conditions in which they lived (determinants of health), and which might affect health outcomes and/or inequity in their area. We defined "local" as being individual communities of place or interest, which may be within a suburb, a village or town or city, or a designated region or geographical boundary (such as a county in the UK). We excluded public participation/influence in decision-making at a national/country level. We thus used a broad definition of public health outcomes to include decisions and actions that might have an effect on health, well-being or social determinants of health in a local population.

Study design - We included European studies of any empirical design (reporting quantitative or qualitative data). We supplemented the empirical literature with additional papers from non-European countries which outlined relevant frameworks and theories. While these sources are typically excluded from systematic reviews, we anticipated that they would offer additional insights or explanatory value regarding mechanisms of effects. We did not set any exclusion criteria on the basis of quality. 
Other criteria - We included papers published in peer-reviewed publications since 2008 , as this covered the period following the global financial crash. We excluded books, theses, and professional magazine articles. We included grey literature from the UK in the form of local evaluations/reports that we were able to identify via online searching, or which were cited in reference lists of included studies.

\section{Information sources}

We drew on expertise developed locally of using theoretical searching, and cluster methodologies to scope a disparate set of literature across different disciplines and databases (17). We searched the following databases for literature published in English since 2008.

- MEDLINE

- EMBASE

- Cochrane Library

- CINAHL (Cumulative Index to Nursing and Allied Health Literature)

- HMIC (Health Management Information Consortium)

- Web of Science (Science Citation Index and Social Science Citation Index

The information specialist on the team carried out several rounds of searching between May and September 2019. Two initial searches in targeted electronic databases (MEDLINE and Web of Science) were run in order to test and refine the search strategy. Following this testing, the search was subsequently adapted and run across a broader selection of social science databases. We also used supplementary searching methods of reference list screening and citation searching. We searched for grey literature using the Open Grey database and websites specific to the UK, and consulted with stakeholders. The full search strategy in an example database is available as additional online material (Additional file 1).

\section{Study selection}

Retrieved citations were downloaded to a reference management system (EndNote Version 9) for screening. Titles and abstracts of retrieved citations were screened by a lead reviewer, with a $10 \%$ sample checked by a second member of the team. Potentially relevant literature was retrieved and assessed for inclusion. Discrepancies were resolved by consensus or referred to a third reviewer if necessary.

\section{Data collection process and data items}

For the empirical studies we extracted data relating to the details of the initiative/programme/strategy, type of participants, summary of results, description of influencing factors and context, and reported associations between elements using a form developed for the review. For studies reporting theories and 
frameworks we extracted: the focus area of the study; name of theory where applicable; and summary of the theory/framework (including hypothesised links between public influence and outcomes).

\section{Quality appraisal and risk of bias}

We used checklists from the Critical Appraisal Skills Programme (18) relevant to each empirical study design, to consider the quality of identified literature where possible. Appraisal checklists were not applicable for predominantly descriptive or theoretical studies.

\section{Methods of synthesis}

We used methods of tabulation, and narrative synthesis to explore the literature identified, and metasynthesis to compare where theories and frameworks informed empirical data. A summary diagram (informed by the theories and frameworks identified) was used to categorise and structure reporting of the evidence.

\section{Results}

\section{Study selection}

We screened a total of 11,218 references found in our electronic database searching, and examined a further 15 potentially relevant reports. We looked in detail at 220 evidence sources and included 44 of these representing 41 individual studies. Figure 1 outlines the process of evidence identification and selection.

\section{This figure illustrates the flow of studies through the review}

\section{Study characteristics}

The included literature was dominated by UK research (see Fig. 2), with the greatest proportion of qualitative or case study design (see Table 1). We supplemented the European empirical literature (35 studies) with nine non-European papers containing theoretical models or frameworks (19-27). These models included the participation chain model (19), social innovation theory (20), a community capacity model (21), community capability model (22), decision process model (25), and the biographical approach (26).

\section{This figure provides a summary of the countries from which the included literature originates}

We identified eight other relevant reviews. The oldest of these was a rapid review of community engagement initiatives completed in 2011 (28). The next was a 2012 review of involvement strategies in 
environmental projects (29). Two 2016 reviews explored evidence on pathways from control to health inequalities,(10) and community capability (22). A review in 2017 explored evidence regarding public and stakeholder engagement in the built environment (30), and another in the same year focused on community engagement (11). The two most recent reviews were a review of the impact of joint decisionmaking on community well-being (31), and a review of opportunities to engage the public in local alcohol decision-making, which also included other local decision-making (32). While these reviews overlapped in some aspects with our review and provided valuable findings regarding potential pathways to outcomes, studies had often been included which described approaches more aligned to consultation than involvement. We therefore extracted only those findings answering our review questions. 
Table 1

Included studies categorised by study design

\begin{tabular}{|l|l|}
\hline Longitudinal & Heritage 2009 \\
& Lawless 2010/2012 \\
& Markatoni 2018 \\
\hline Qualitative & Carlisle 2010 \\
& Carpenter 2008 \\
& Chadderton 2012 \\
& De Andrade 2016 \\
& Deas 2013 \\
& Farmer 2018 \\
& Fitzgerald 2018 \\
& Lewis 2018/Orton 2017/ Reynolds 2018 \\
& Li 2015 \\
& Nimegeer 2016 \\
& Parker 2011 \\
& Brookfield 2017 \\
Carton 2017 & De Freitas 2015 \\
Durose 2010 & Froding 2011 \\
Froding 2013 & Joerin 2009 \\
& Lehoux 2012 \\
& Luyet 2012 \\
Case study &
\end{tabular}




\begin{tabular}{|c|c|}
\hline Longitudinal & $\begin{array}{l}\text { Heritage } 2009 \\
\text { Lawless 2010/2012 } \\
\text { Markatoni } 2018\end{array}$ \\
\hline \multirow[t]{7}{*}{ Review } & Attree 2011 \\
\hline & Brunton 2017 \\
\hline & George 2016 \\
\hline & Leyden 2017 \\
\hline & McGrath 2019 \\
\hline & Pennington 2018 \\
\hline & Whitehead 2016 \\
\hline \multirow[t]{4}{*}{ Cross sectional (survey) } & Curry 2012 \\
\hline & Fuertes 2012 \\
\hline & Kimberlee, 2008 \\
\hline & Linzalone 2017 \\
\hline \multirow[t]{5}{*}{ Mixed method } & Garnett 2017 \\
\hline & Heritage 2019 \\
\hline & Iconic consulting 2014 \\
\hline & Naylor 2019 \\
\hline & Popay 2015 \\
\hline \multirow[t]{3}{*}{ Discussion } & Freudenberg 2011 \\
\hline & Hagelskamp 2018 \\
\hline & Healy 2009 \\
\hline
\end{tabular}

\section{Quality appraisal}

Where appropriate, studies were appraised using checklists for each study design (see Additional File 1). The quality of the included quantitative literature was very limited, with very few studies collecting data at more than one time point, predominantly descriptive reporting, and little use of statistical analysis. Case studies also often focused on narrative reporting. There was greater quality in the qualitative studies, with these providing depth of insight into participant views and experiences. The review studies in general had been carried out using rigorous systematic methods.

\section{Synthesis of results}


Given the complexity of the findings, we developed a summary diagram (Fig. 3) to provide a structure for categorising and reporting the evidence, drawing on the models and theories we identified.

The synthesis outlines evidence within each of the four categories of the diagram in turn, moving from the outer to inner tiers. The first section of the synthesis outlines the differing forms and functions of initiatives described in the literature (outer tier). This is then followed by evidence of influencing factors, which were reported to either enable or constrain initiatives (including those relating to organisations, participatory processes and communities). The next section outlines evidence of the effects of approaches (including on relationships, individuals, communities, and the decision-making/participatory process itself). The final section (inner tier) relates to evidence of longer-term health and health inequalities impacts of approaches to increase public participation and influence.

Figure 3. Summary diagram of the evidence

This figure illustrates the structure of the reporting of evidence in four tiers from initiative form and function, influencing factors, intermediate outcomes, and longer term impacts.

\section{Characteristics of approaches to increase public participation and influence}

The literature outlined initiatives to increase public participation and influence in local decision-making and action in relation to eleven different local issue areas/decision-making topics: planning and the built environment (five studies), health inequalities and social exclusion (one study), environmental management (three studies), urban regeneration (three studies), alcohol licencing (three studies), citizen welfare (one study), community empowerment (two studies reported in four papers), service reconfiguration and community capability building (one study), health services (three studies), road safety (one study), and community involvement/participation generally (three studies).

Included sources labelled their approaches to public participation and influence in different ways: as "engagement activities" with young people (one study); neighbourhood planning (four studies); planning aid (one study); a social inclusion partnership (one study); a citizen sensor network (one study); participatory health impact/health needs assessment (three studies); asset-based approaches (three studies); financial investment (four studies reported in seven papers); alcohol licencing committee participation (two studies)' and healthy cities networks (one study). Authors provided limited detail regarding exactly what activities formed part of the approach undertaken, and even less regarding how activities undertaken were intended to support public participation and influence, and with what effects on other wider determinants of health and health inequity. It was therefore often difficult to determine exactly what the intended function of people's participation and influence was within decision-making processes and local actions.

Specific activities recommended to support participation and influence included: the use of threedimensional graphics (33), use of virtual tools to help visualise a local area, social media, geographical 
information systems and decision support systems (30), newsletters and establishment of a communication plan (34). Paying attention to mechanisms for sharing information with the wider community was reported to be key (35), with clear feedback and demonstration of commitment required (36). Authors of one study cautioned that potentially a large number of meetings and public forums could be required to overcome barriers and mistrust (37). Studies highlighted that communities needed adequate knowledge and skills to enable involvement, for example mechanisms need to be put in place to support their contribution at meetings $(31,38,39)$.

Theoretical papers provided more information about the intended functions of differing forms of activity to support people's participation and influence in local decision-making and action. Activities such as "inviting people to participate", "'listening" and "responding" were highlighted as important, given that these are experienced as a vote of confidence in people's personal competencies. They are seen to provide a sense of being able to make a difference; a signal that public views are valued and that participation has been influential (that people have made a difference). This in turn encourages further participation/involvement $(19,27)$. The use of facilitators was emphasised as a theoretically important activity given that they can act as bricoleurs (community builders) who help connect community participants to other local resources $(20,27)$. Citizens' contextualised understanding of local problems can then be brought into decision-making processes alongside other stakeholder's understandings of what may be feasible solutions (20).

Studies outlined how facilitators can also help create empowering spaces (protective niches) where community participants are "given permission" to consider issues and changes needed. In these spaces, trusting relationships between different stakeholders can grow, promoting knowledge exchange and collective learning within decision-making and limits professional dominance $(19-21,27)$. Activities supporting relationship-building between community organisations, civic groups and government stakeholders can provide opportunities for the public to advocate more effectively for policy changes of benefit locally (23).

Finally, theoretical papers highlighted the importance of activities such as training, technical assistance and community organisation/mobilising, which functioned by strengthening community capacity/collective capabilities to participate and exert an influence (e.g. via the development of civic skills, civic knowledge, social/political awareness) (21-23). Community-based activity with residents was also highlighted as important in supporting community capacity: developing resident's knowledge (and ownership of that knowledge) for use in advocating for change and in decision-making (21).

Theoretical papers therefore highlighted that approaches should involve a set of activities functioning together to support public participation and influence (rather than just "one" intervention). Empirical papers similarly emphasised that differing forms of activity may be required to be influential within decision-making (39-41), and that activities will differ depending on context (42) and the breadth, depth and reach intended (34). While much of public involvement tends to be "top down" (30, 32, 43, 44), the literature emphasised the importance of moving towards a "bottom up" approach; starting from the 
communities' agendas and not the organisations' $(39,40)$. Authors cautioned of the need to ensure that aspirations of involvement do not turn into a cosmetic exercise (30)

Sources further highlighted that activities, and their intended function in enhancing public participation and influence may need to change over time (23), as aspirations grow or policies change (28), and enthusiasm may wane (46). Studies emphasised the need for continuity of public involvement, with particular consideration of sustainability, organisational commitment and the funding required $(28,39$, $43,47-49)$. One paper drawing on social innovation theory (20) argued for sustainability to be grounded in a shared vision and expectations across communities and other stakeholders.

Four studies noted that the timing of initiatives to increase participation is important, and that involvement should take place in early phases of decision-making $(37,38,45,50)$. The benefit of a holistic community approach was emphasised (48), with involvement of multiple agencies (46). The need for formal and organised involvement strategies was emphasised (41), together with having an organisation policy in place to drive change (47). There should be strengthening of people's perception of the possibilities (51), and effective governance to support and drive through initiatives (34).

\section{Factors influencing the characteristics of different approaches and outcomes}

The literature identified diverse factors which affect the characteristics, and effects of approaches and actions. We categorised these as factors relating to: organisations; participatory processes; and communities.

\section{Organisations}

Organisational factors described predominantly related to local government, as a key policy actor in local settings, but also extended to factors relating to other "governing authorities" (42) such as local health boards.

Studies emphasised how changes to the local government operating context could influence how much focus involvement was given internally (47). A study of alcohol licencing in the UK, for example, reported that re-elections and changes of individuals in key posts within alcohol licencing boards "completely changed the climate" (44). The increasing use of private companies to provide local services (such as refuse collection) was noted to provide additional challenges to public involvement, as local government distanced themselves from decisions made, and the established routes for public opportunities to influence became ineffective (52).

Several studies identified the influence of organisational culture on support provided to, or the approach taken towards public participation and influence. Organisational culture could determine perceptions and organisational values regarding whether and how to involve the public (including cynicism about participation) and whether there was leadership on participation $(32,38-40,48,53)$. Views held could be different at different levels within organisations, with high-level support needed for cultural 
transformations and changes in mind-sets, if public participation with scope for influence is to become the norm (38). Training for staff in involvement approaches was recommended, together with support to enable them to work in new ways (39). Several studies noted where a lack of skills and/or knowledge in community engagement had adversely effected an organisation's ability to involve the public successfully $(32,38-40,48)$.

Papers outlining theories and frameworks also drew attention to organisational factors either fostering, sustaining or undermining approaches to public participation and influence, and outcomes (19). Personal, professional, and organisational attitudes shaped the willingness to listen during public participation, with those who appreciate the value of public participation and knowledge most prepared to engage and/or consider new ways of working $(19,24,27,40)$. Studies described "asymmetries of power" between "expertise" and public insights and understanding (24). Whether the public were acknowledged organisationally as legitimate participants could shape an organisation's capacity to value the potential richness and complexity of involvement (26). One paper highlighted that for those organisations with governing authority, their approach to involvement could depend on their understanding of the type of problem (42).

\section{Participatory processes}

The key role of power inequalities as an influencing factor during processes of participation was emphasised $(44,52,54,55)$. Two studies noted dilemmas regarding how far initiatives instigated by local government to increase involvement should give communities decision-making powers when there is disparity between what local government perceive to be acceptable and sustainable, and resident expectations of what could be achieved $(46,56)$. Other authors pointed to often differing national priorities and funding streams which constrain choices available to local decision-making $(45,55)$. Councillors in one study for example highlighted how despite their best intentions, power at a local level could be limited by top down decision-making systems (40).

The literature highlighted that time was a key factor, in order to allow sufficient input from communities and to build relationships $(32,37-40,45,48,52,54)$, and also to develop shared trust (21). Authors highlighted that there can be potential for mismatches between community expectations of change, and time scales required to achieve it $(30,32,37,38,43,45,57)$.

\section{Community-related}

A sizeable volume of studies highlighted challenges in involving a wide cross-section of any community in involvement initiatives $(34,35,41,45-47,56-58)$. Authors noted the often small number of individuals participating, and that increased involvement/influence often did not extend beyond "the few", with a particular need to empower those who are typically excluded. Studies described community apathy, disenfranchisement, reluctance to engage, lack of awareness of opportunities, communities being bombarded by researchers, and participation of only those who were highly motivated $(30,38,39,43,44)$. An evaluation of an initiative to increase public involvement in local planning for example noted that the 
small number of individuals who drove activities were typically male homeowners aged over 59, with prior experience of the planning system (57).

Concepts of community capacity and resilience (social and environmental capital existing in individuals and a community) were highlighted as important in influencing a communities' ability to be involved (21, 41). Participation might be most effective when community capacity is at a "tipping point", or state of readiness, which could be harnessed by additional resource or stimulus $(11,47)$.

The conceptual framework developed by Brunton et al. (11) refers to multiple factors which can influence whether or not community members participate including: personal gain (wealth/health/skills), community benefits ideas about altruism/responsible citizenship. The authors emphasised that needs, issues and motivations of communities should provide a foundation to structure how initiatives to encourage community involvement develop. One study (19) recommended a "mobilising" approach via direct invitations and approaches to participate, in order to enhance the involvement and influence of marginalised groups, migrants, and people from ethnic minority backgrounds.

The literature emphasised that the concept of "communities" is often unclear and fluid, creating challenges to increasing community involvement. Authors described how some residents may not identify with a geographical area, that changes in the demographic of the local area can adversely influence the cohesiveness of a community, and how there can be shifting concepts of community boundaries $(34,40,45,46,57,59,60)$. Cultural variance was noted as important to recognise, with language and literacy affecting whether and how some members of a community participate (39). Authors outlined the potential for sub-community tensions to shape participatory processes, with differing perceptions of amenities, territorial pockets, and perceptions of improvement not being equal across all areas $(34,35,39,41,44,47,55)$.

Papers drawing on theoretical models echoed the need to fully consider varying definitions of community (11), raising questions about how "the public" is defined (42), and cautioning that any quest to involve "the ordinary citizen" is challenging (26).

Two studies emphasised the importance of community hubs and other social spaces as facilitators of participation. In one (47) authors reported that meeting places and community facilities were critical to an initiative to develop and maintain resident engagement and influence in local issues. The other (20) similarly noted the role of an empowering space in involvement.

\section{Outcomes}

In common with many other public health interventions, the pathway from involvement initiatives to social determinant effects is complex, multi-faceted and distal, and may be direct or indirect (10). We identified several frameworks which offered varying typologies of outcomes $(10,21,23,31,32,42,46$, 58). We endeavoured to synthesise these models in our reporting, which distinguishes four main types of effects: effects on relationships (civic sector alliances); effects on the decision-making process and actions; effects on relationships and assets within communities; and effects on individuals. 


\section{Effects on relationships (civic sector alliances)}

Four empirical papers concluded that increased involvement in decision-making leads to the formation of new relationships between local government and residents. Involvement can lead to the development of new personal contacts and partnerships, and a shared sense of responsibility $(30,36,53,60)$. The outcome of increased trust was central in these improved relationships $(21,23,31,36,37,46)$. Other empirical studies noted outcomes of increased joint commitment (41), and development of a shared vision (59).

\section{Effects on decision-making and action}

A key effect to consider is whether approaches to increase public participation and influence actually have an effect on actions and local decision-making choices that affect peoples' lives and where they live. Here, the evidence was mixed. Eight papers from seven studies $(32,36-38,46,50,54,56,58)$ suggested approaches to increase involvement enable greater public influence on decisions. For example one (38) reported that community participation in plans for a major housing development appeared to have resulted in revised plans integrating the preferred options of the community. Another (32) concluded that community priorities had been incorporated into alcohol licensing plans. An Italian study suggested that a participatory health impact assessment had led to community empowerment, which in turn was associated with more equitable decision-making about local health needs and priorities (37). Another paper (23) claimed there was evidence of participatory budgeting approaches influencing decisionmaking on spending priorities (the allocation/distribution of public funds), particularly choices about capital projects and/or physical infrastructure improvements (e.g. green space, transportation, streets, recreation, renovating schools). Other papers suggested that approaches to support participation and influence could go as far as to reshape policy choices in ways that deflect threats to local environments; reducing the unequal distribution of environmental stressors/risks that affect health and health inequalities $(10,21)$.

We looked for evidence of the process whereby these impacts might come about. Seven empirical studies reported that public participation and influence had the intermediate effect of providing additional/alternative knowledge during the decision-making process, which could potentially then affect the decisions made $(32,33,37,40,50,52,56)$. One study (40) highlighted that public involvement enabled two types of knowledge to be brought to the planning processes- local expertise, and specialist knowledge (although the authors noted that this knowledge could be viewed by planners as being "unreliable"). Another study of planning decisions argued that approaches to increase involvement (partnership in planning) had led to community consensus about what was needed and therefore more effective planning (37). Papers reporting theories and frameworks echoed the potential for approaches which aimed to increase participation and influence, to lead to the inclusion of different forms of knowledge within the decision-making process $(19,42)$. This knowledge could raise local government awareness of community needs that were "forgotten/invisible" under "business as usual" (23). Public 
involvement therefore could resolve knowledge "deficits" and/or lead to innovative ideas and co-designed solutions (20).

While reports of influence (perceived or actual) on local decision-making and actions, and increased knowledge brought to the decision-making process suggest positive effects of approaches to increase involvement, literature also reported uncertainty regarding effects, or evidence of little effect. A description of an initiative to increase public participation in waste management decision-making in Wales (52) for example outlined how planning systems precluded public participation. Short time limits on responses can similarly adversely affect the ability of community groups to mobilise (61). Lack of transparency in decision-making processes makes it often difficult to tell whether or how public participation and influence has shaped the decisions made (33). One paper highlighted that there is a need to clearly distinguish involvement from consultation if the effects are to be discerned (32).

\section{Effects on relationships and assets within communities}

Increased knowledge in terms of a positive outcome for communities (rather than the decision-making process) was emphasised in six included empirical studies. One (56) reported that participation workshops led to improved health literacy and health system literacy for community participants. A road safety initiative for young people increased knowledge of community issues amongst participants (33). Similarly, a study of community-led planning reported that participants had better awareness of local issues and needs (36). A study from The Netherlands likened additional community knowledge to gaining "information-power" (54).

Papers emphasised other community outcomes arising from processes of participation, including: improved social relationships and forms of mutual support, and networks of connections (11); group confidence and sense of entitlement to participate (19); identity, community-minded behaviour, social capital, connectivity and cohesion, resources for change, sense of community, intergenerational connectivity (47); and the development of civic skills, knowledge and social and political awareness (23). These intermediate outcomes in turn were described as increasing collective efficacy and power to take action of benefit to people in a particular area (11), and/or to advocate for change (21). New communities of interest can be formed, as a shared vision for an area is developed (59).

Four studies drew such associations between participation and control and empowerment. One (40) theorised that community participation in planning provided opportunities to be actively involved and influence, which then led to increased control and empowerment, with the outcome of individuals and communities becoming more resilient. Similarly, authors of a study evaluating a community action model suggested that a "strengthened community" could be associated with increased capacity to influence decision-making (50).

A note of caution however, is provided by one study which found that following an intervention (a large funded programme) there were increases in the intermediate outcome of "feeling part of the community", but there did not appear to be statistically significant change in community outcomes $(46,58)$. Two 
papers reported potential adverse outcomes, with increased involvement leading to conflicts within communities, and differing points of view regarding priorities for funding $(45,59)$. Another described how one project had failed to even start, due to disputes within the community (41).

\section{Effects on individuals}

Empirical studies reported benefits for individuals in terms of well-being, self-confidence, self-esteem, and physical, emotional and mental health $(28,31,33)$. Also, increased individual efficacy (32) and individual empowerment $(28,31,37)$. One study $(28)$ noted benefits in particular for individuals from "at risk" population groups, with increased social integration potentially having a protective effect on individual health and quality of life. Theoretical papers echoed the beneficial effects of participation for individuals in terms of: increased sense of ability to make a difference, strengthened resources, motivation, confidence, perceived success and psychological empowerment $(19,23,27)$.

However, the literature also highlighted potentially adverse effects for individuals. Authors described: exhaustion, frustration, stress, and fatigue from taking part $(28,31,45)$, and how engagement can become dispiriting and disempowering, resulting in scepticism, limited expectations of participation and a reluctance to engage further $(11,28,32,36,52)$.

\section{Health and health inequalities impacts}

We scrutinised the literature for evidence of any impact on individual or community health, health inequalities or health determinants. A systematic review of the effects of joint decision-making suggested a potential association between increased control and a reduction in inequalities (31). Another review hypothesised a potential association between community empowerment and personal psychological health and well-being, which then leads to a cumulative health improvement at the population level (28). A study of community participation in health impact assessments drew a potential association between improved evidence-informed decision-making and population health improvement (52). Authors of one paper hypothesised that the development of civic skills, knowledge and social and political awareness via participation could potentially be linked to improved mental health outcomes in the longer term (23).

An empirical evaluation of a large funded programme $(46,58)$ however, found no relationship between participation/perceived influence in decision-making, and impacts on health. A paper reporting multiple qualitative case studies on involvement in planning decision-making (57) found some limited evidence of a narrowing of the gap between more and less deprived households on some outcomes, but also potential to widen inequalities. Exclusion of marginalised groups may potentially reinforce inequalities $(32,38,61)$, and a lack of representativeness which may then lead to a lack of validity of decisions made $(34,56,62)$.

\section{Constrained resources}

A particular focus of this review was the actual or potential impact of constrained resources on approaches to increase public participation and influence, given the challenging economic context for local governments, communities and their organisational partners. 
Included studies drew attention to the often insufficient costing of participation within tight budgets (30, $32,38,39)$. A qualitative study of an asset-based approach for example outlined how limited engagement was the result of practicalities, budget and funding cuts, and lack of resources (39).

Papers reported how the requirement for efficiency in local government tends to be framed as inconsistent with public participation and influence, with "costs" sometimes used as a justification for local government not attempting approaches to increase the involvement of members of the public in local decision-making $(38,52,57)$. Studies highlighted that public participation was not high up the budgetary agenda $(30,32,39)$, and there was competition for resources between different projects (45). Time and resource are also required from communities themselves, and participants in one study viewed the costs of participation as "barely justifiable in regard to what was achieved" (40).

Financial sustainability needs to be central if ideas, knowledge and solutions developed through participatory approaches are to thrive; with the prevailing macro-level (policy) regime a key influence on this (20). Sustainability of funding is key if trust with communities is to be developed and organisations are to avoid "leaving communities when the money ran out" (39). Papers drew attention to how low investment in public services, declining neighbourhood assets and/or limits to people's personal resources (e.g. money, power, information) can undermine individual or community capacity to participate $(10,21)$.

Space for participation, including community hubs and other social spaces within communities are important, with weak economic conditions perpetuating limited investment by developers in community assets and facilities (47).

\section{Discussion}

Our systematic review provides a range of insights into how initiatives to increase people's influence in local decision-making and action might work, the potential effects on other wider determinants of health and inequity, and how constrained resources might shape or impact these initiatives.

Identifying and characterising initiatives that seek to enhance influence is challenging. We found that empirical evidence labels and characterises initiatives to enhance public participation and influence in different, and sometimes unclear ways. Studies identified tended to provide limited detail about specific activities that form part of the approach, and even less information on how activities are intended to, or did function to enhance participation and influence in practice. In this sense, much of the empirical evidence was "under-theorised", showing limited engagement with intervention logics or theoretical works that exist on the topic. This type of "under-theorising" has been noted by others in relation to the public health sciences more broadly $(63,64)$. Yet the results of the review suggest the "disconnect" between some of the empirical and theoretical works could usefully be bridged by more heavily drawing on evidence underpinned by theory, particularly to offer insights into different points of intervention within complex local systems of governance (i.e. at regional, city and/or neighbourhood levels). 
Greater theoretical engagement could support more rigorous evaluation of the effectiveness of initiatives; promoting better understanding of the highly complex and distal hypothesised change pathways within local systems, and how and where participation and influence might impact on the social, material and political conditions that shape health and inequities. Currently, the empirical evidence base regarding the effectiveness of approaches is dominated by descriptive accounts. If investment is to be made by local or national governments, other organisations, or indeed communities themselves, particularly in times of resource-constraint, there is an urgent need to clarify the forms and functions of different activities in terms of participation and influence, and make more explicit the hypothesised pathways to improvements.

Complex forms of initiatives like participatory health impact assessment and participatory budgeting might function to support community capacities and strengthen relationships/civic alliances. In turn, this might lead to more effective advocacy on policy changes that may help reduce health inequities (e.g. more equitable distribution of public funds for services) (23). Approaches like community organising or community-based participatory research activities may also act on community capacities, as well as help build relationships with other stakeholders. Together, these may help people living in more disadvantaged circumstances advocate for changes that can improve health and wellbeing (21-23). In contrast, forms of participation such as local government or other statutory organisations inviting people to participate, listen and respond, may function in a different way; by demonstrating to people that their competences/views are valued, reinforcing motivations to participate, and a sense that people can make a difference to living conditions $(19,27)$.

Our results highlight that initiatives to enhance participation and influence often involve a range of different activities or forms of approach that may function together over time, requiring considerable relational and political work on the part of those involved. The evidence identified suggests that particularly effective areas to prioritise for action within local systems of governance in order to enhance participation and influence are:

1. Involvement should be viewed as a process over several years rather than a one-off activity related to a specific project or initiative.

2. Developing community competences/capabilities (or "'community capacities"') is essential for participation and influence.

3. Developing relationships between organisations and communities including connecting people, to promote sharing of knowledge and other resources.

4. Creating spaces and shared spaces for safe and more equitable forms of participation/interaction and knowledge-sharing, both between community members and between community and "professionals".

5. Changing institutional culture and associated practices (e.g. within local government) to promote participation and influence. This will likely require training to enable people to work in new ways. 
The review suggests a need for context-specific support to enable change processes in all of these priorities for action, given the variety of factors in organisations, communities and individuals that can influence participatory initiatives. For example, facilitators could support the development of individual and/or community capacities including self-confidence, civic skills and knowledge, and social and political awareness. They may also be valuable in helping build relationships by connecting networks of local people with knowledge to share, and external actors such as public sector managers, and health agencies. At the same time, facilitators can help to create "protective" or "shared spaces" in which community participants feel comfortable in considering/discussing local issues or needs; supporting trust to grow; and knowledge to be exchanged $(19-21,27)$. Facilitators could even come from outside the community according to a recent study evaluating use of an anthropologist supporting local government staff at a time of deep spending cuts to have "different conversations" with citizens (65). Wider research nevertheless warns that critical reflection is needed on the role and associated power dynamics of those who work at the interfaces in this way $(66,67)$.

Many of the other factors identified as affecting participation and influence in the review reflect deepseated and structural issues within local governance systems. For example, community-related factors highlight how participatory initiatives inevitably become entangled in the differentiated histories, experiences and identities of people living in an area and in pre-existing processes of inclusion and exclusion operating within communities (68). Many of the organisational factors identified reflect systemic issues affecting the capacity of statutory organisations to work effectively with citizens (69, 70). Particularly significant were asymmetries in power between professionals/expertise and public/lay knowledge, and the review draws attention to the way in which lay knowledge often challenges the dominance and institutional power of "experts" and how professionals characterise "problems" $(69,70)$. Yet, the review also highlights that, when lay knowledge is valued and legitimised institutionally, this can result in fresh understandings of issues and policy priorities, that better reflect the realities of those facing multiple disadvantages (69), and thus potentially more equitable future decision-making and allocation of public funds.

The evidence included in the review particularly highlighted actual or potential influence on prioritysetting, and choices about capital projects and/or physical infrastructure improvements (e.g. green space, transportation, streets, recreation, renovating schools). In other words, approaches seemed particularly to influence how wider environmental or material determinants of health are seen or understood by those in positions of decision-making power, and thus potential for reducing the unequal distribution of environmental stressors/risks that affect health and inequity.

Importantly, despite the focus on politics and power in the included evidence, as with the point alreadymade above, we argue that these concepts were also "under-theorised". Hay (16) argues for a need to investigate more explicitly forms of power/influence within local governance systems, and to draw out how influence can manifest: for example, whether it is immediately visible and observable (e.g. via discussion, persuasion, coercion) or results more indirectly, over the longer-term, through redefining institutional structures. Other authors have similarly argued for more explicit engagement with concepts 
of politics and power within public health research, to provide additional insights into how, why and for whom policy initiatives work $(63,71)$.

There are a number of significant ways in which constrained resources can impact the effectiveness of approaches to participation and influence within local governance systems, for example reduced individual and community capacity through declining investment in public services and neighbourhoods, and limited personal resources. This raises questions about the effectiveness of initiatives in the current economic context, particularly given the anticipated social and economic crisis resulting from the COVID19 pandemic $(12,14)$. Recent reports highlight threats, particularly in more "ignored" communities; not only due to the loss of civic spaces such as libraries and youth centres, but also because resource constraints can deeply affect people's sense of collective identity and control (72-74). There may however, be an opportunity to harness the learning and confidence gained by those involved in the collective efforts to respond to the unmet need in their communities (75). Local government another other statutory organisations may also be able to build on the relationships formed out of the emergency response to the COVID-19 pandemic (76). The challenge now is for both parties to build on and sustain these relationships developed in time of crisis, as well as for local governments that didn't engage successfully, to learn from those that did.

For statutory organisations like local government, changed institutional practices to promote participation and influence will require bold leaders to take risks and embrace thinking and acting differently, including valuing and legitimising lay capabilities and knowledge (77). Yet it is unclear whether such risk-taking will take place, particularly if dominant institutional perceptions of public participation remain as a "cost" to organisations. For citizens, our results highlight that, while there can be benefits at an individual level for self-confidence and self-esteem, being involved in initiatives involves social/emotional costs as participation can be stressful, frustrating and not always rewarding. If, as anticipated, the social and economic costs resulting from the COVID-19 pandemic unequally impact those already experiencing multiple disadvantages, mitigating these "costs of participating" will be an even greater, but essential challenge to overcome if approaches are to impact on health equity.

\section{Limitations}

Searching for literature on complex and poorly defined topics such as public involvement is known to be challenging, and there is the possibility that our searches did not identify all studies of relevance. We used supplementary methods of reference list and citation searching to help mitigate any limitations in our electronic database searching, but recognise that documents such as relevant grey literature may not have been included. It was challenging to distinguish between studies which reported public involvement or influence, from those relating to public consultation; and we may have inadvertently excluded studies where we were unable to discern the intention to involve, or where there was actual involvement of the public in decision-making. While a key focus of our review was on decision-making during times of resource constraint, we were able to identify only limited data relating to this. 


\section{Conclusions}

Review of the literature on initiatives to increase public participation and influence in local decisionmaking and action to address determinants of health, highlights a lack of transparency and theoretical engagement regarding how these initiatives are intended to act within local governance systems. Despite this, we have identified possible areas to prioritise for action to enhance participation and influence including: supporting community capabilities; supporting relationships between organisations and communities; creating spaces for safe/equitable interaction and knowledge-sharing; and changing institutional practices/rules/culture within organisations (e.g. local government). Yet if investment is to be made, particularly in times of resource-constraint, there is an urgent need to clarify both form and functions of different activities, and situate within complex and longer-term pathways to improvements in other determinants of health and inequity. While there is potential to build on the momentum of civic participation emerging from self-mobilising community emergency response to the COVID-19 pandemic, initiatives may be at risk during times of limited resourcing: undermining individual/community capacities to participate, and requiring organisational leaders to think/act differently. The review suggests a need for support to enable change processes, particularly in response to deep-seated and structural issues within local governance systems, and more explicit engagement with concepts of politics and power.

\section{Declarations}

\section{Ethics approval and consent to participate}

As secondary research this study did not require ethical approval.

\section{Consent to Publish}

Not applicable

\section{Competing interests}

The authors have no financial or non-financial competing interests to declare.

\section{Availability of data and materials}

All data is available from the corresponding author on reasonable request.

\section{Funding}


This study is funded by the National Institute for Health Research (NIHR) School for Public Health Research (Grant Reference Number PD-SPH-2015). The views expressed are those of the authors and not necessarily those of the NIHR or the Department of Health and Social Care.

\section{Author contributions}

SB led the review and wrote the initial version of the manuscript. AB contributed to the review processes and led on writing the background and discussion sections of the manuscript. CL and RM contributed to the review processes and contributed to editing of drafts of the manuscript. MC carried out the electronic database searching and contributed to the methods section of the manuscript.

\section{Acknowledgements}

Not applicable

\section{References}

1. World Health Organization. Closing the gap in a generation. Health equity through action on the social determinants of health. Final Report of the Commission on Social Determinants of Health. Geneva: World Health Organization; 2008.

2. Dahlgren GW. M. Policies and Strategies to Promote Social Equity in Health. Stockholm: Institute for Futures Studies; 1991.

3. Popay JE, Hernández S, Johnston M, Mathieson H, Rispel J. L. Understanding and Tackling Social Exclusion: Final Report to the WHO Commission on Social Determinants of Health From the Social Exclusion Knowledge Network. Geneva: World Health Organization; 2008.

4. Marmot MA, Boyce J, Goldblatt T, Morrison P. J. Health Equity in England: The Marmot Review 10 years On. London: The Health Foundation; 2020.

5. Europe WHO. Healthy, prosperous lives for all: the European Health Equity Status Report. Copenhagen: World Health Organization Europe; 2019.

6. Development OfEC-oa. Innovative Citizen Participation and New Democratic Institutions: Catching the Deliberative Wave. Paris: Organisation for Economic Co-operation and Development; 2020.

7. Department for Digital C. Media and Sport. Community Life Survey 2018-19. London: Department for Digital, Culture, Media and Sport; 2019.

8. Nations U. Sustainable Development Goals 2020 [Available from: https://www.un.org/sustainabledevelopment/sustainable-development-goals/.

9. World Health Organization Europe. Addressing the social determinants of health: the urban dimension and the role of local government. Copenhagen: World Health Organization Europe; 2012. 
10. Whitehead M, Pennington A, Orton L, Nayak S, Petticrew M, Sowden A, et al. How could differences in 'control over destiny' lead to socio-economic inequalities in health? A synthesis of theories and pathways in the living environment. Health Place. 2016;39:51-61.

11. Brunton G, Thomas J, O'Mara-Eves A, Jamal F, Oliver S, Kavanagh J. Narratives of community engagement: a systematic review-derived conceptual framework for public health interventions. BMC Public Health. 2017;17.

12. Stuckler D, Reeves A, Loopstra R, Karanikolos M, McKee M. Austerity and health: the impact in the UK and Europe. Eur J Pub Health. 2017;27:18-21.

13. Lowndes VM. K. Weathering the perfect storm? Austerity and institutional resilience in local government. Policy Politics. 2013;41(4):533-49.

14. Bambra C, Riordan R, Ford J, Matthews F. The COVID-19 pandemic and health inequalities. Journal of Epidemiology and Community Health. 2020:jech-2020-214401.

15. Arnstein SR. A Ladder of Citizen Participation. Journal of the American Institute of Planners. $1969 ; 35(4): 216-24$.

16. Hay C. Divided by a Common Language: Political Theory and the Concept of Power. Politics. 1997;17(1):45-52.

17. Booth AC. Systematic searching for theory to inform systematic review: is it feasible? Is it desirable. Health Information Libraries Journal. 2015;32:220-35.

18. Programme CAS. CASP Checklists Oxford: Critical Appraisal Skills Programme; 2018 [Available from: https://casp-uk.net/casp-tools-checklists/.

19. De Freitas C, Martin G. Inclusive public participation in health: Policy, practice and theoretical contributions to promote the involvement of marginalised groups in healthcare. Soc Sci Med. 2015;135:31-9.

20. Farmer J, Carlisle K, Dickson-Swift V, Teasdale S, Kenny A, Taylor J, et al. Applying social innovation theory to examine how community co-designed health services develop: using a case study approach and mixed methods. BMC Health Services Research. 2018;18.

21. Freudenberg N, Pastor M, Israel B. Strengthening community capacity to participate in making decisions to reduce disproportionate environmental exposures. Am J Public Health. 2011;101:123S30.

22. George AS, Scott K, Mehra V, Sriram V. Synergies, strengths and challenges: findings on community capability from a systematic health systems research literature review. BMC Health Services Research. 2016;16:623.

23. Hagelskamp C, Schleifer D, Rinehart C, Silliman R. Participatory Budgeting: Could It Diminish Health Disparities in the United States? J Urb Health. 2018;95(5):766-71.

24. Healy S. Toward an epistemology of public participation. J Environ Manage. 2009;90(4):1644-54.

25. Joerin F, Desthieux G, Beuze SB, Nembrini A. Participatory diagnosis in urban planning: proposal for a learning process based on geographical information. J Environ Manage. 2009;90(6):2002-11. 
26. Lehoux P, Daudelin G, Abelson J. The unbearable lightness of citizens within public deliberation processes. Soc Sci Med. 2012;74(12):1843-50.

27. Li KK, Abelson J, Giacomini M, Contandriopoulos D. Conceptualizing the use of public involvement in health policy decision-making. Soc Sci Med. 2015;138:14-21.

28. Attree P, French B, Milton B, Povall S, Whitehead M, Popay J. The experience of community engagement for individuals: a rapid review of evidence. Health Social Care in the Community. 2011;19(3):250-60.

29. Luyet V, Schlaepfer R, Parlange MB, Buttler A. A framework to implement Stakeholder participation in environmental projects. J Environ Manage. 2012;111:213-9.

30. Leyden KM, Slevin A, Grey T, Hynes M, Frisbaek F, Silke R. Public and Stakeholder Engagement and the Built Environment: a review. Current Environmental Health Reports. 2017;4(3):267-77.

31. Pennington A, Watkins MB, South AM, Corcoran J. R. A systematic review of evidence on the impacts of joint decision-making on community wellbeing. London: What Works Centre for Wellbeing; 2018.

32. McGrath M, Reynolds J, Smolar M, Hare S, Ogden M, Popay J, et al. Identifying opportunities for engaging the 'community' in local alcohol decision-making: A literature review and synthesis. Int $\mathrm{J}$ Drug Policy. 2019;74:193-204.

33. Kimberlee R. Streets ahead on safety: young people's participation in decision-making to address the European road injury 'epidemic'. Health Social Care in the Community. 2008;16(3):322-8.

34. Lewis S, Bambra C, Barnes A, Collins M, Egan M, Halliday E, et al. Reframing "participation" and "inclusion" in public health policy and practice to address health inequalities: Evidence from a major resident-led neighbourhood improvement initiative. Health Social Care in the Community. 2019;27(1):199-206.

35. Heritage Z, Dooris M. Community participation and empowerment in Healthy Cities. Health Promotion International. 2009;24(Suppl 1):i45-55.

36. Parker G, Murray C. Beyond tokenism? Community-led planning and rational choices: findings from participants in local agenda-setting at the neighbourhood scale in England. Town Planning Review. 2012;83(1):1-28.

37. Linzalone N, Coi A, Lauriola P, Luise D, Pedone A, Romizi R, et al. Participatory health impact assessment used to support decision-making in waste management planning: A replicable experience from Italy. Waste Manag. 2017;59:557-66.

38. Carpenter JB. S. Approaches to democratic involvement: widening community engagement in the English planning system. Planning Theory Practice. 2008;9(2):227-48.

39. de Andrade M. Tackling health inequalities through asset-based approaches, co-production and empowerment: ticking consultation boxes or meaningful engagement with diverse, disadvantaged communities? Journal of Poverty Social Justice. 2016;24(2):127-41.

40. Curry N. Community Participation in Spatial Planning: Exploring Relationships between Professional and Lay Stakeholders. Local Government Studies. 2012;38(3):345-66. 
41. Markantoni M, Steiner A, Meador JE, Farmer J. Do community empowerment and enabling state policies work in practice? Insights from a community development intervention in rural Scotland. Geoforum. 2018;97:142-54.

42. Garnett K, Cooper T, Longhurst P, Jude S, Tyrrel S. A conceptual framework for negotiating public involvement in municipal waste management decision-making in the UK. Waste Manag. 2017;66:210-21.

43. Froding K, Geidne J, Elander I, Eriksson C. Towards sustainable structures for neighbourhood development? Healthy city research in four Swedish municipalities 2003-2009. Journal of Health Organization Management. 2013;27(2):225-45.

44. Fitzgerald N, Winterbottom J, Nicholls J. Democracy and power in alcohol premises licensing: A qualitative interview study of the Scottish public health objective. Drug Alcohol Rev. 2018;37(5):60715.

45. Carlisle S. Tackling health inequalities and social exclusion through partnership and community engagement? A reality check for policy and practice aspirations from a Social Inclusion Partnership in Scotland. Critical Public Health. 2010;20(1):117-27.

46. Lawless P, Pearson S. Outcomes from Community Engagement in Urban Regeneration: Evidence from England's New Deal for Communities Programme. Planning Theory Practice. 2012;13(4):50927.

47. Deas ID. J. Building community capacity under 'austerity urbanism': Stimulating, supporting and maintaining resident engagement in neighbourhood regeneration in Manchester. Journal of Urban Regeneration Renewal. 2013;6(4):365-80.

48. Durose C, Lowndes V. Neighbourhood Governance: Contested Rationales within a Multi-Level Setting - A Study of Manchester. Local Government Studies. 2010;36(3):341-59.

49. Popay JWM, Carr-Hill R, et al. The impact on health inequalities of approaches to community engagement in the New Deal for Communities regeneration initiative: a mixed-methods evaluation. Public Health Research. 2015;312.

50. Fuertes C, Pasarin MI, Borrell C, Artazcoz L, Diez E. Group of Health in the N. Feasibility of a community action model oriented to reduce inequalities in health. Health Policy. 2012;107(23):289-95.

51. Froding K, Elander I, Eriksson C. Neighbourhood development and public health initiatives: who participates? Health Promotion International. 2012;27(1):102-16.

52. Chadderton C, Elliott E, Hacking N, Shepherd M, Williams G. Health impact assessment in the UK planning system: the possibilities and limits of community engagement. Health Promotion International. 2013;28(4):533-43.

53. Naylor CW. D,. A citizen-led approach to health and care. Lessons from the Wigan Deal. London: Kings Fund; 2019.

54. Carton L, Ache P. Citizen-sensor-networks to confront government decision-makers: Two lessons from the Netherlands. J Environ Manage. 2017;196:234-51. 
55. Durose CF, Lupton J, Richardson R. L. Towards the 'Big Society': what role for neighbourhood working?: evidence from a comparative European study. London: Centre for Analysis of Social Exclusion, London School of Economics and Political Science; 2011.

56. Nimegeer A, Farmer J, Munoz SA, Currie M. Community participation for rural healthcare design: description and critique of a method. Health Social Care in the Community. 2016;24(2):175-83.

57. Brookfield K. Getting involved in plan making: participation in neighbourhood planning in England. Environment Planning C-Politics Space. 2017;35(3):397-414.

58. Lawless P, Foden M, Wilson I, Beatty C. Understanding Area-based Regeneration: The New Deal for Communities Programme in England. Urban Studies. 2009;47(2):257-75.

59. Orton L, Halliday E, Collins M, Egan M, Lewis S, Ponsford R, et al. Putting context centre stage: evidence from a systems evaluation of an area based empowerment initiative in England. Critical Public Health. 2017;27(4):477-89.

60. Reynolds J. Boundary work: Understanding enactments of 'community' in an area-based, empowerment initiative. Critical Public Health. 2018;28(2):201-12.

61. consulting I. Strengthening the community voice in alcohol licensing decisions in Glasgow. London: Iconic Consulting; 2014.

62. Reynolds JE. M. Identifying mechanisms to engage the community in local alcohol decision making: Insights from the CELAD study. London: School for Public Health Research; 2018.

63. de Leeuw E, Clavier C, Breton E. Health policy - why research it and how: health political science. Health Research Policy Systems. 2014;12(1):55.

64. Hawe P, Shiell A, Riley T. Complex interventions: how "out of control" can a randomised controlled trial be? BMJ. 2004;328(7455):1561-3.

65. Naylor CW. D. A citizen-led approach to health and care. Lessons from the Wigan Deal. London: Kings Fund; 2019.

66. Long N. Development Sociology: Actor Perspectives. London: Routledge; 2001.

67. Wallerstein N. Power between evaluator and community: research relationships within New Mexico's healthier communities. Soc Sci Med. 2001;49(1):39-53.

68. Cornwall A, Schattan V, Coelho P. Spaces for Change? The Politics of Citizen Participation in New Democratic Arenas. 2007.

69. K. PCPJS. Developing a model to enhance the capacity of statutory organisations to engage with lay communities. Journal of Health Services Research \& Policy. 2002;7(1):34-42.

70. Popay J, Williams G, Thomas C, Gatrell T. Theorising Inequalities in Health: The Place of Lay Knowledge. Sociol Health IIIn. 1998;20(5):619-44.

71. Bambra C, Fox D, Scott-Samuel A. Towards a politics of health. Health Promotion International. 2005;20(2):187-93.

72. Young I. Inclusion and Democracy. Oxford: Oxford University Press; 2002. 
73. Gregory D. Skittled Out? The Collapse and Revival of England's Social Structure. London: Local Trust; 2018.

74. Marmot MA, Boyce J, Goldblatt T, Morrison P. J. Health Equity in England: The Marmot Review 10 Years On. London: Institute of Health Equity; 2020.

75. Macmillan R. Rapid Research COVID-19. Grassroots action: the role of informal community activity in responding to crises. Briefing 3. London: Local Trust; 2020.

76. Robinson D. The Moment We Noticed. London: Relationships Project; 2020.

77. Ham C. Engaging people and communities will help avoid a resurgence of covid-19. The BMJ Opinion. 2020.

\section{Figures}

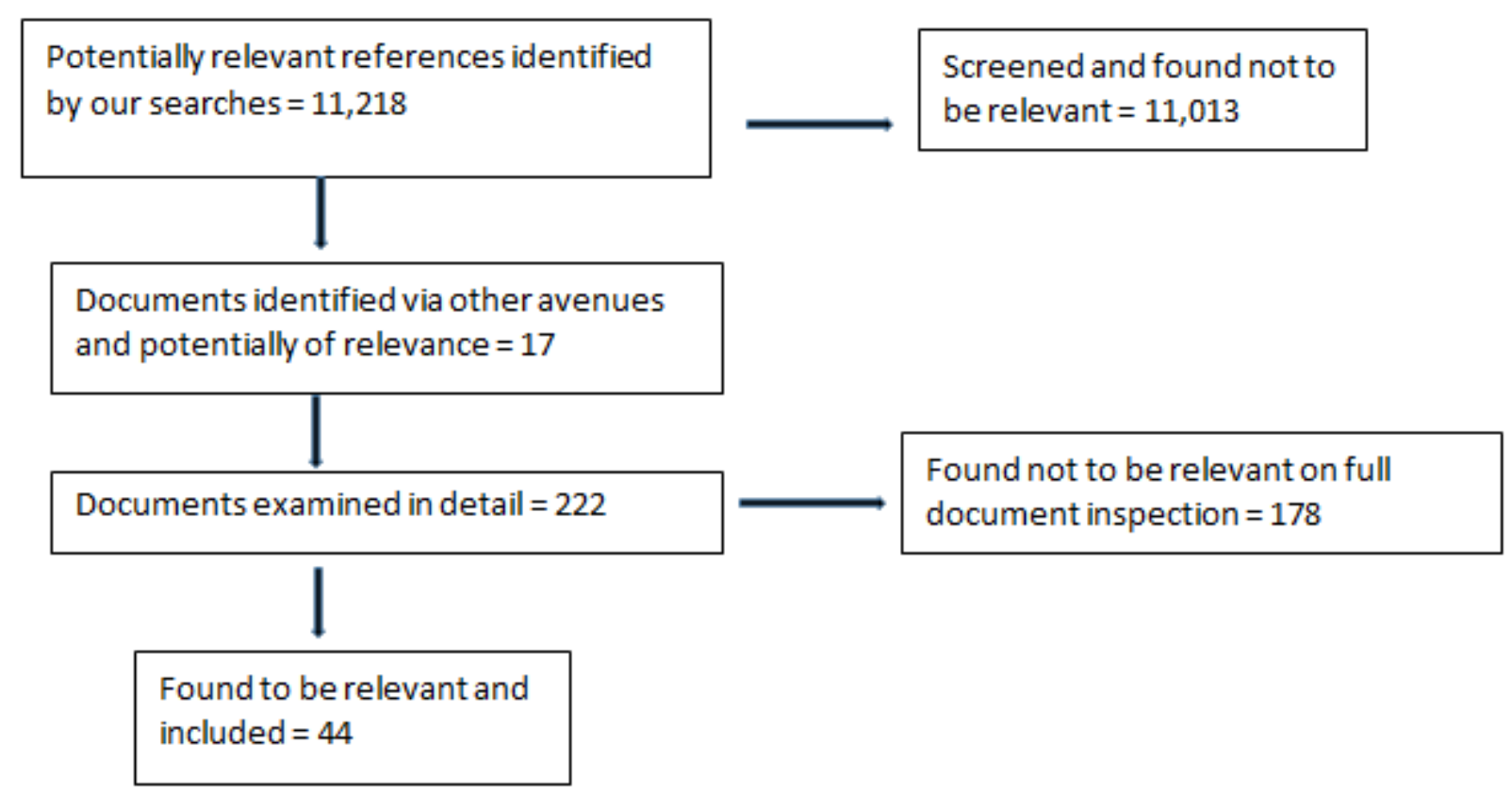

\section{Figure 1}

The process of evidence identification and inclusion This figure illustrates the flow of studies through the review Study characteristics 


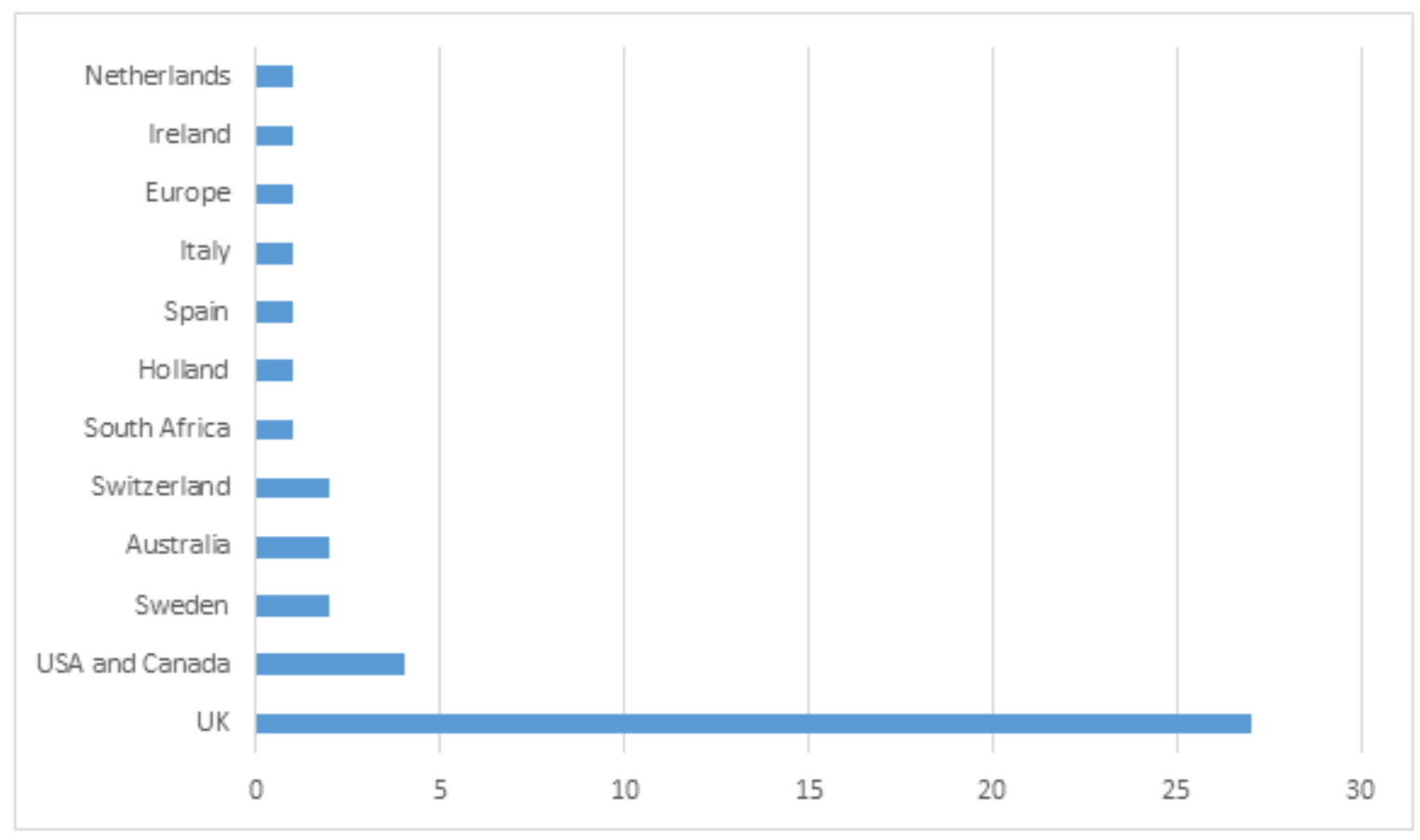

Figure 2

Country of origin This figure provides a summary of the countries from which the included literature originates 


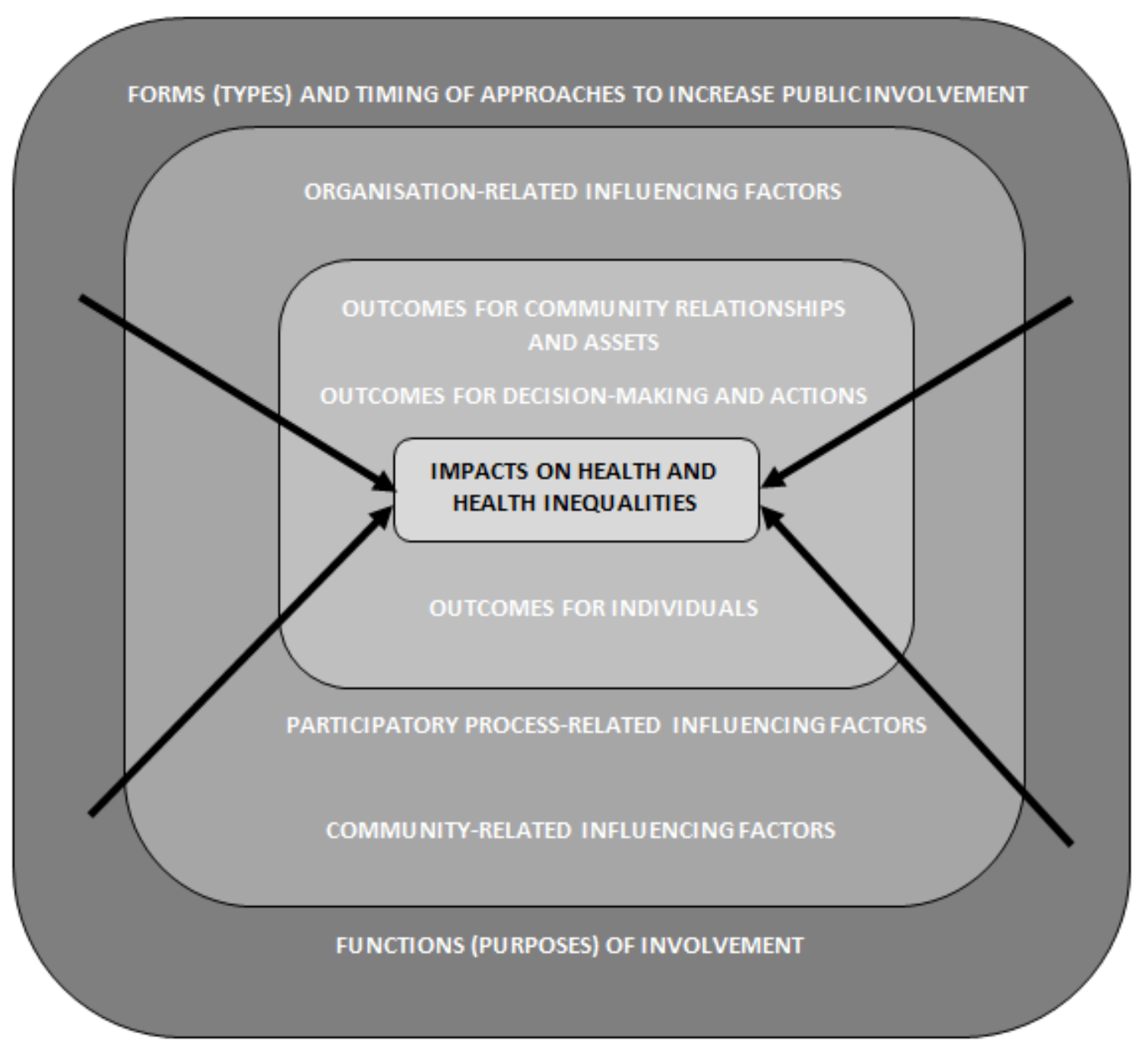

\section{Figure 3}

Summary diagram of the evidence This figure illustrates the structure of the reporting of evidence in four tiers from initiative form and function, influencing factors, intermediate outcomes, and longer term impacts. Characteristics of approaches to increase public participation and influence

\section{Supplementary Files}

This is a list of supplementary files associated with this preprint. Click to download.

- PRISMAchecklistPCpaper.doc

- pcpaperAdditionalFile1.docx

- PCpaperAdditionalFile2.docx 